\title{
Angiotensin IV upregulates the activity of protein phosphatase $1 \alpha$ in Neura-2A cells
}

\author{
Dan Wang ${ }^{1,2}$, Peng Xue ${ }^{1}$, Xiu Lan Chen ${ }^{1}$, Zhen Sheng Xie ${ }^{1}$, Fu Quan Yang ${ }^{1}$, Li Zheng ${ }^{1 凶}$, Tao Xu ${ }^{1 凶}$ \\ ${ }^{1}$ National Key Laboratory of Biomacromolecules, Institute of Biophysics, Chinese Academy of Sciences, Beijing 100101, China \\ ${ }^{2}$ University of Chinese Academy of Science, Beijing 100049, China \\ $\triangle$ Correspondence: zhengli@moon.ibp.ac.cn (L. Zheng), xutao@ibp.ac.cn (T. Xu) \\ Received January 15, 2013 Accepted March 19, 2013
}

\begin{abstract}
The peptide angiotensin IV (Ang IV) is a derivative of angiotensin II. While insulin regulated amino peptidase (IRAP) has been proposed as a potential receptor for Ang IV, the signalling pathways of Ang IV through IRAP remain elusive. We applied high-resolution mass spectrometry to perform a systemic quantitative phosphoproteome of Neura-2A (N2A) cells treated with and without Ang IV using stable-isotope labeling by amino acids in cell culture (SILAC), and identified a reduction in the phosphorylation of a major Ser/Thr protein phosphorylase 1 (PP1) upon Ang IV treatment. In addition, spinophilin (spn), a PP1 regulatory protein that plays important functions in the neural system, was expressed at higher levels. Immunoblotting revealed decreased phosphorylation of p70S6 kinase $\left(\mathrm{p} 70^{\mathrm{S6K}}\right)$ and the major cell cycle modulator retinoblastoma protein (pRB). These changes are consistent with an observed decrease in cell proliferation. Taken together, our study suggests that Ang IV functions via regulating the activity of PP1.
\end{abstract}

KEYWORDS angiotensin IV, PP1a, cell proliferation, p $70^{\text {S6 }}$ kinase, spinophilin

\section{INTRODUCTION}

Angiotensin IV (Ang IV), a hexapeptide metabolite of Ang II, has drawn considerable attention because of its effect on regulating the process of learning and memory. Albiston identified the Ang IV receptor in bovine adrenal membranes to be insulin-regulated aminopeptidase (IRAP) (Albiston et al., 2001). Ang IV inhibits IRAP catalytic activity by binding to the catalytic site of IRAP (Lew et al., 2003). Ang IV can facilitate memory in both normal (Braszko et al., 1988; Lee et al., 2004) and memory-compromised rodents (Wright et al., 1999). Studies on the mechanism of Ang IV action over recent decades have shown that Ang IV has effects on increasing the intracellular calcium level (Dostal et al., 1990; Dulin et al., 1995; Chansel et al., 2001; Handa, 2001), regulating the proliferation of different tissue cells, and on glucose uptake in insulin responsive tissues and the brain (Fernando et al., 2008). However, the exact mechanism by which Ang IV enhances memory remains to be elucidated.

Protein phosphorylase 1 (PP1) is a major protein Ser/Thr phosphatase. It is ubiquitously expressed in all eukaryotic cells, and plays important roles in a wide range of cellular processes, including meiosis and cell division, apoptosis, protein synthesis, metabolism, cytoskeletal reorganization, and the regulation of membrane receptors and channels (Fernandez et al., 1992; Cheng et al., 2000; Wang et al., 2011). Several isoforms of PP1, PP1 $\alpha, P P 1 \beta$ and PP1y, are known in mammals. These various isoforms are highly similar and ubiquitously expressed, except for the testis-enriched PP1 $y_{2}$. PP1 can be regulated by inhibitory subunits that directly suppress its activity (Takai et al., 1987; Bialojan and Takai, 1988), and by many regulatory subunits that determine its substrate specificity and subcellular localization (Bollen, 2001; Cohen, 2002).

Here, in order to detect changes in protein phosphorylation occurring in N2A cells when stimulated with Ang IV, we used a quantitative strategy based on stable isotope labeling of amino acids in cell culture (SILAC) to generate a phosphoproteome of N2A cells. This study showed that the phosphorylation status of many proteins changes upon Ang IV stimulation. Among these protein, PP1 and its relative proteins drew our great interest. We found that Ang IV stimulation reduced the phosphorylation level at its Thr320 residue. At the same time, spinophilin, one of its regulatory subunits, was found to have an increased expression and an augmented accumulation on peri-membrane and nucleus area. As a result, Ang IV up-regulates PP1's ac- 
A

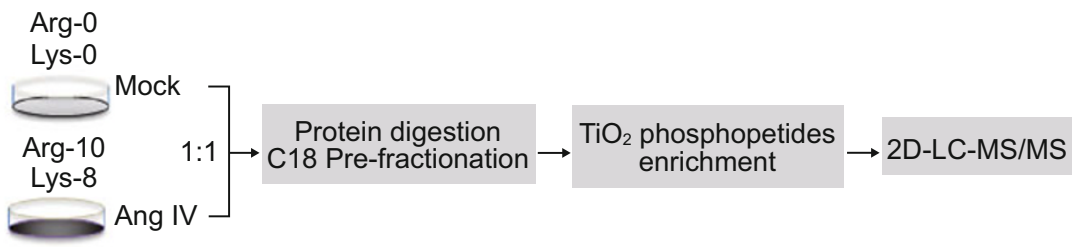

B

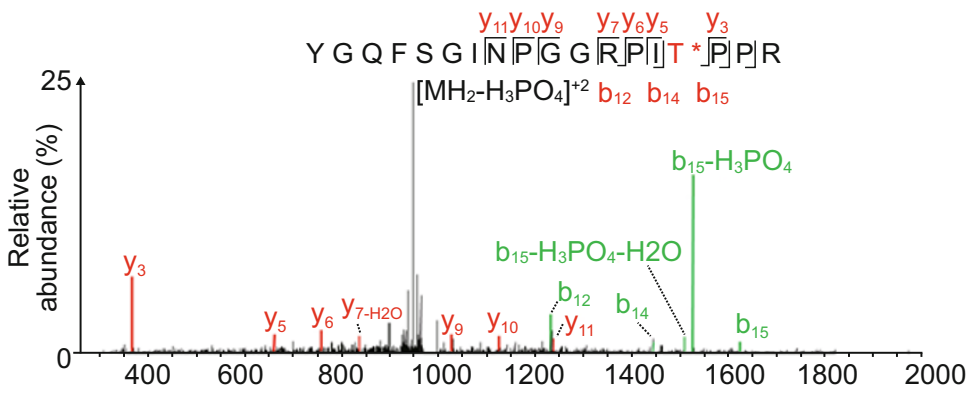

C

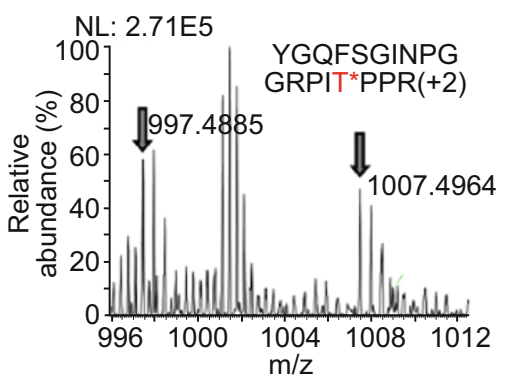

E

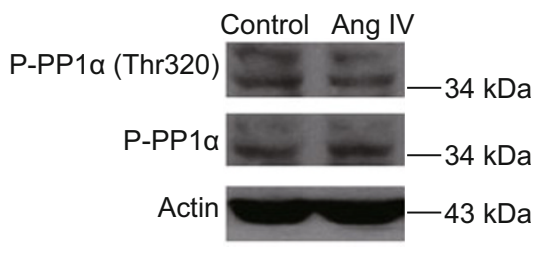

D

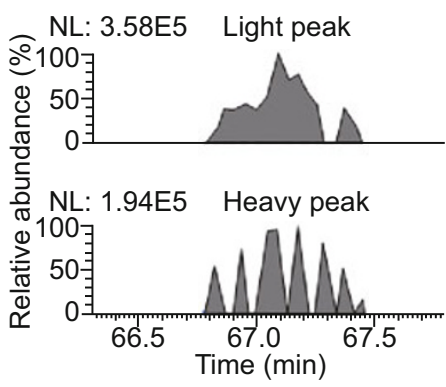

$\mathrm{F}$

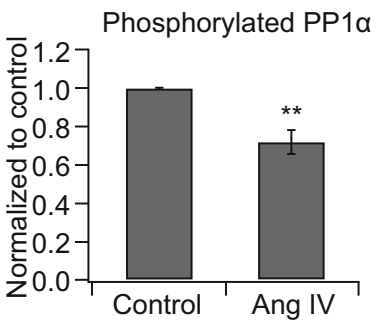

Figure 1. Ang IV decreases the phosphorylation of PP1 at Thr320. (A) Procedures involved in generating the quantitative phosphoproteome, including SILAC, C18 prefractionation, $\mathrm{TiO}_{2}$ phosphopeptide enrichment and 2D-LC-MS/MS. (B) MS/MS spectrum of phosphopeptide YGQFSGINPGGRPIT*PPR (asterisk indicates phospho-Threonine, Thr320) from the serine/threonine-protein phosphatase PP1-alpha catalytic subunit (PPP1 $\alpha$ ). Fragment ions assigned to both $y$-ions and b-ions are labeled. (C) MS spectrum of SILAC pairs of phosphopeptides YGQFSGINPGGRPIT*PPR with a charge state of +2 . The peaks are marked by arrows, that on the left being the normal peptide and that on the right being the Arg-10di-labeled peptide. (D) Extracted ion chromatograms for SILAC pairs of phosphopeptides YGQFSGINPGGRPIT*PPR (+2). (E) On treatment with $10 \mathrm{nmol} / \mathrm{L}$ Ang IV for $30 \mathrm{~min}$, the phosphorylation of PP1 $\alpha$ at the Thr320 site decreased compared with the non-treated control. Two specific bands were detected on each lane, may reflect a different status of modification of PP1a. (F) Statistical analysis of immnuoblotting experiments. The phosphorylation of PP1 $1 \alpha$ at the Thr320 site in treated groups was $72 \pm 6 \%$ (mean \pm SD) that of the control $(n=5)$. tivity towards many of its substrates. This effect causes many changes such as proliferation and cell cycle arrest in neuronal cells.

\section{RESULTS}

\section{Ang IV decreases phosphorylation of PP1 $\alpha$ at Thr320}

In order to systematically examine the changes in protein phosphorylation which occur when Ang IV acts on N2A cells, we performed a global SILAC-based quantitative phosphoproteome of N2A cells (Fig. 1A). Examination of the resulting data drew our attention to one especially interesting phosphorylation event, a 0.24 -fold decrease in the phosphorylation of the Serine/threonine-protein phosphatase PP1-alpha catalytic subunit (PPP1 $\alpha$ ) at Thr320 after 30 min of Ang IV stimulation (Fig. 1B-D). The phosphorylation at this site is reported to inhibit the activ- ity of PP1 $\alpha$ and play an important part in cell cycle regulation (Berndt, 1999; Li et al., 2007).

To further confirm the regulation of PP1 1 a by Ang IV, we investigated its phosphorylation level by Western blotting using an anti-phospho-PP1 $\alpha$ antibody. We incubated N2A cells with $10 \mathrm{nmol} / \mathrm{L}$ Ang IV for $30 \mathrm{~min}$, and detected phosphorylated PP1 $\alpha$ by immunoblotting with a Phospho-PP1 $\alpha$ (Thr320) specific antibody. A significant decrease (nearly $27 \%$ compared to the basal condition) in phosphorylation was observed (Fig. 1E and 1F), indicating the potential of Ang IV to up-regulate the activity of PP1 1 .

Ang IV increases the expression of spinophilin and changes its subcellular location

In addition to being directly suppressed by phosphorylation, 
PP1's activity towards its numerous targets is regulated by its interactions with a large number of regulatory subunits $(R$ subunits) which target PP1 $\alpha$ to distinct subcellular locations and specific targets (Terry-Lorenzo et al., 2002). Spinophilin (spn, neurabin II), one of these PP1 regulatory proteins, has been shown to perform important functions in the nervous system, altering spine morphology and density, synaptic plasticity and neuronal migration (Allen et al., 1997; Ragusa et al., 2010). Using immunoblotting, we found that after treatment with $10 \mathrm{nmol} / \mathrm{L}$ Ang IV for $4 \mathrm{~h}$, the expression of spn increased to approximately 1.3-fold that of the control (Fig. 2A and 2B). Immunofluorenscence results showed that spn is enriched in the cell peri-membrane area of N2A cells where it colocalizes with F-actin, and accumulates in nuclei (Fig. 2C). Interestingly, after cells were treated with Ang IV for $2 \mathrm{~h}$, the amount of spn at both these two subcellular locations increased significantly (Fig. 2C). It has been reported that when phosphorylated on two serine sites, spn dislocates from the membrane-associated fraction to the cytosol (Hsieh-Wilson et al., 2003). This altered distribution of spn may reflect the ability of Ang IV to regulate its post translational modification.

\section{Ang IV inhibits cell proliferation and arrests the cell cycle}

The significant changes in spn drew our attention to its other biological functions, such as that in cell growth, as it appears to be a strong growth suppressor in colony formation efficiency (CFE) assays (Vivo et al., 2001). We tested the effect of Ang IV on the proliferation of neuronal cells. N2A cells were cultured in 96-well plates and treated with different amounts of Ang IV. After $20 \mathrm{~h}$, the number of cells in each group was counted with a cell counting kit-8(CCK8). The proliferation rate of cells treated with $10 \mathrm{nmol} / \mathrm{L}, 100 \mathrm{nmol} / \mathrm{L}$, and $1000 \mathrm{nmol} / \mathrm{L}$ Ang IV decreased to $\sim 0.89, \sim 0.85$ and $\sim 0.76$, respectively (Fig. $3 \mathrm{~A}$ ), demonstrating that Ang IV inhibits proliferation of these cells. We also tested this effect on other cells; HEK293 cells which are reported to have no IRAP expression, and L6 rat myoblasts that express normal IRAP. We also established a stable cell line from $\mathrm{L} 6$ cells called 2F1, which expresses abundant exogenous IRAP (Fig. 3B). Intriguingly, we found that the more IRAP expressed in a given cell line, the greater the effect of Ang IV on inhibiting its proliferation (Fig. 3C).

This decrease in cell proliferation suggested the possible involvement of a cell cycle delay at certain steps. We therefore examined whether Ang IV stimulation can cause cell cycle arrest and which phase is affected. After incubating with $10 \mathrm{nmol} / \mathrm{L}$ Ang IV for $20 \mathrm{~h}$, we found that the percentage of N2A cells in $G_{1} / S$ phase increased significantly compared to the control group, while the percentage of cells in the $G_{2}$ phase decreased at the same time (Fig. 3D). The same experiment was performed in HEK293 cells, but no significant change was observed (data not shown). This cell cycle arrest at $G_{1}$ phase can be related to the decrease of phosphorylation at Thr320 of PP1a which we described above. In dividing mammalian cells, regulation of PP1 is crucial for maintaining a normal cell cycle.
A

B

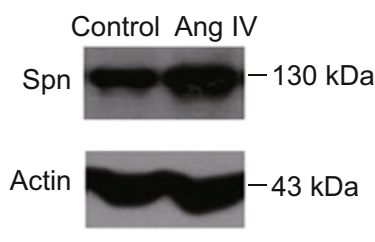

C

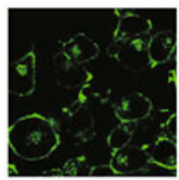

F-actin

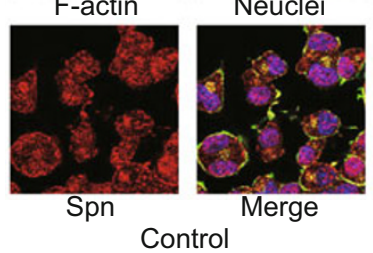

Spn expression
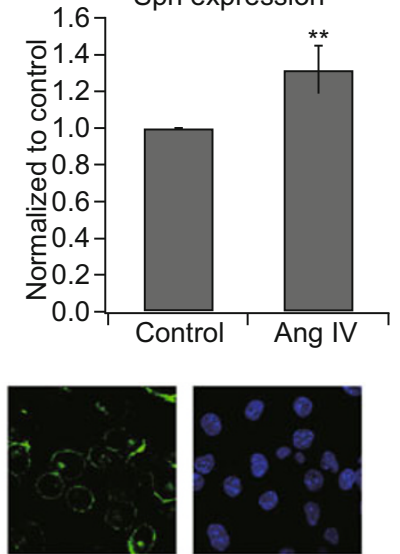

F-actin

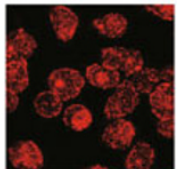

Spn

Ang IV

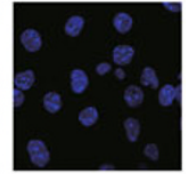

Neuclei

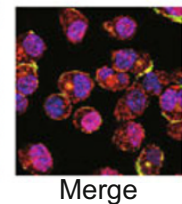

D

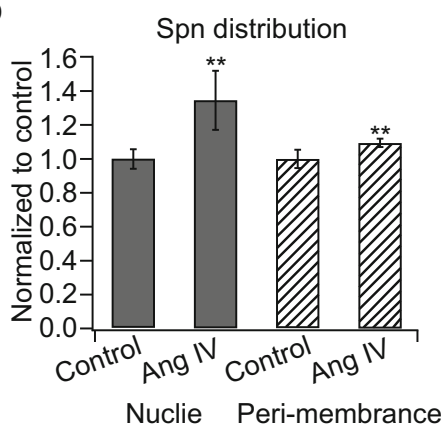

Figure 2. Ang IV alters spinophilin expression and distribution. (A and B) On stimulation with $10 \mathrm{nmol} / \mathrm{L}$ Ang IV for $4 \mathrm{~h}$, the expression level of spn increased to $1.31 \pm 0.13$ (mean \pm SD) fold that of the control $(n=5)$. (C) Immunofluorescence assay showing that spn accumulates at both the peri-membrane and nucleus of N2A cells. Spn colocalizes with both F-actin stained with FITCphalloidin and nuclei labeled by DAPI. (D) On Ang IV stimulation, more spn was detected in both the nucleus and peri-membrane $(1.34 \pm 0.17$ and $1.09 \pm 0.02$ (mean $\pm S D$ ) fold increases relative to the control, respectively), as determined by fluorescence intensity of spn in these two areas.

PP1 $\alpha$ is phosphorylated by cyclin-dependent kinase CDK1 and CDK2 on Thr320, and this inhibition is essential for cells to enter the $S$ phase (Liu et al., 1999). Moreover, a similar $G_{1} /$ $S$ cell arrest occours when a constitutively activate mutant of PP1a (T320A) is induced in cells (Berndt et al., 1997).

\section{Ang IV dephosphorylates $\mathrm{p} 70^{\mathrm{S} 6 \mathrm{~K}}$ and $\mathrm{pRB}$}

In all eukaryotic cells, the progression of cell growth is driven 


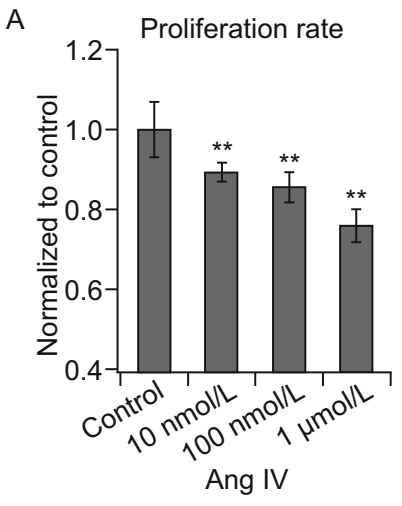

B

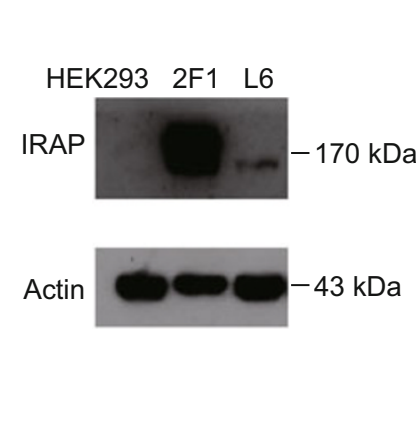

C
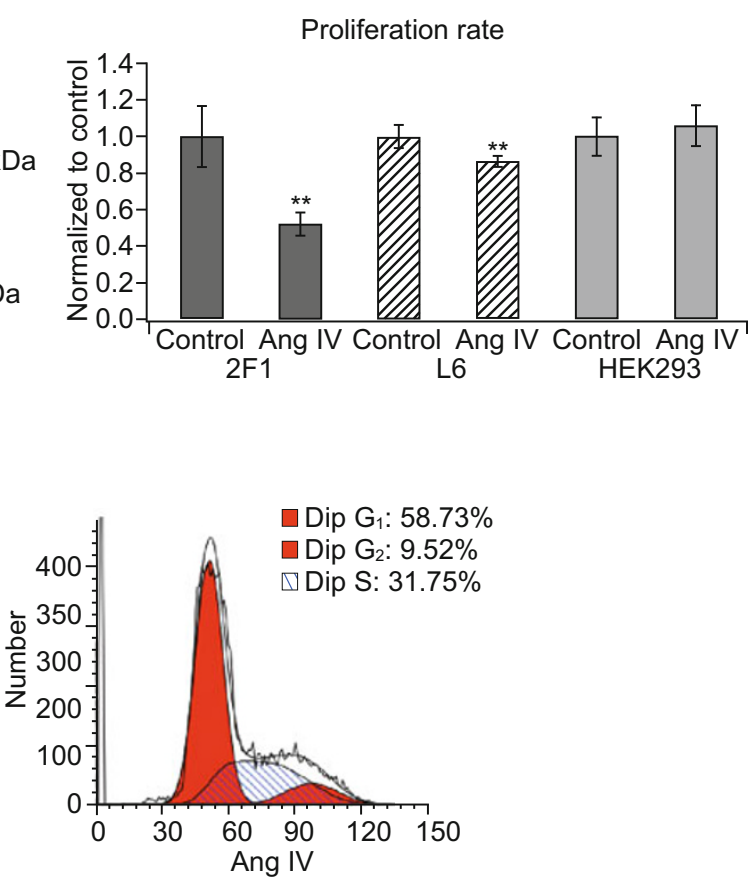

Figure 3. Ang IV stimulation causes a delay in cell proliferation and cell cycle arrest. (A) Proliferation of N2A cells under various concentrations of Ang IV, as determined with a CCK8 kit. Cell number decreased in an ANG IV dose-dependent manner. (B and C) Immunoblotting showed that in HEK293, 2F1 and L6 cell lines, no, abundant and minor expression of IRAP was detected, respectively. The relative effect of Ang IV on inhibiting proliferation of these three cell lines is consistent with the level of IRAP expression. (D) Ang IV caused $\mathrm{G}_{1}$ arrest in the cell cycle of N2A cells. Results presented are representative of at least 5 independent experiments performed with similar results.

by multiple phosphorylations of key regulatory proteins. The level of phosphorylation of these proteins determines whether the cell will proliferate, withdraw from the cell cycle, or die. To investigate how Ang IV causes such changes in cell progress, we examined some of these related proteins regulated by PP1.

$\mathrm{P}^{\mathrm{S} 6 \mathrm{~K}}$ is a key enzyme involved in cell proliferation and cell cycle regulation. This kinase is activated by multiple stimuli including mitogens, insulin and serum (Chung et al., 1994; Chou and Blenis, 1995). It has been reported that P70 ${ }^{\text {S6K }}$ interacts competitively with PP1 for spn. By dephosphorylating P70 ${ }^{\mathrm{S6K}}$, PP1 inactivates this kinase and dissociates it from spn (Burnett et al., 1998). The ability of Ang IV to decrease cell proliferation led us to examine the activity of P70 ${ }^{\mathrm{S} 6 \mathrm{~K}}$ under Ang IV stimulation. Western blotting results showed that, after treatment with $10 \mathrm{nmol} / \mathrm{L}$ Ang IV, the phosphorylation level of $\mathrm{P} 70^{\mathrm{S} 6 \mathrm{~K}}$ is significantly lower than in control cells (Fig. 4A and 4B).

Dephosphorylation of retinoblastoma protein $\mathrm{pRB}$, a tumor suppressor protein, is thought to play a critical role in controlling the $G_{1} / S$ transition. PP1 $\alpha$ is proved to be the dominant modulator in this process. In late $G_{1}, P P 1$ is inhibitorily phosphorylated by CDK on Thr320, thus loses its activity to maintain $\mathrm{pRB}$ in hypophosphorylation status. This step is crucial for cells to enter the $S$ phase (Dou et al., 1995; Liu et al., 1999). In view of this, we examined the phosphoryla- tion level of pRB during the cell cycle under the stimulation of Ang IV. Using Western blotting with an antibody against phosphorylated pRB (S807), we found that the phosphorylation level of $\mathrm{pRB}$ in cells is normal. After incubated with Ang IV for $30 \mathrm{~min}$, however, the phosphorylation level of pRB is significantly decreased, to $79 \%$ of the control ones (Fig. 4C and 4D).

\section{DISCUSSION}

The classical renin-angiotensin system (RAS) consists of circulating rennin which acts on angiotensinogen to produce Ang I, which in turn is converted into Ang II by angiotensin-converting enzyme ACE. Other RAS peptides generated from Ang II, including Ang III, Ang IV and Ang 1-7, have been shown to be biologically active (Chansel et al., 1998). Recent studies suggest that Ang IV has important regulatory functions in cognition, renal metabolism and cardiovascular damage, as well as in regulating cell growth in cardiac fibroblasts, endothelial cells and vascular smooth muscle cells (Li et al., 2002; Ruiz-Ortega et al., 2007). The normal physiological level of Ang IV is about $8.6 \pm 1.1 \mathrm{pg} / \mathrm{mL}$ in human serum and exerts its function via specific Ang IV receptors (Shibasaki et al., 1999). This biologically active peptide has attracted increasing interest following 
A

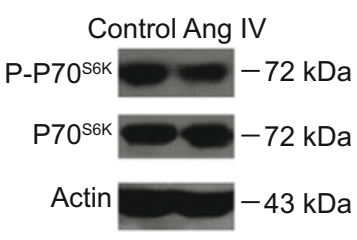

B

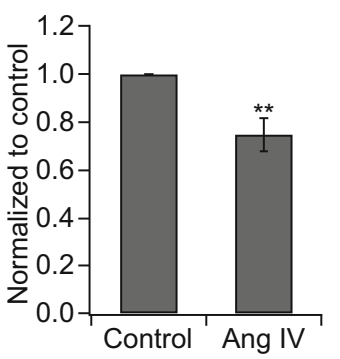

C

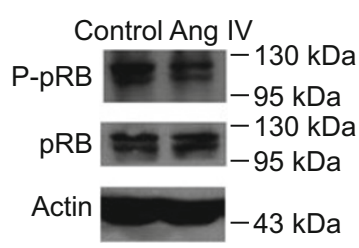

D

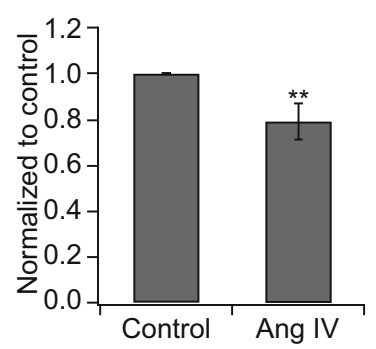

Figure 4. Ang IV causes dephosphorylation of certain PP1 substrates. (A and B) P-P70 ${ }^{\text {S6K }}$ in cells decreases to $75 \pm 7 \%$ (mean $\pm \mathrm{SD}$ ) that of the control after treatment with $10 \mathrm{nmol} / \mathrm{L}$ Ang IV for $30 \mathrm{~min}(n=6)$. (C and D) P-pRB decreased to $0.79 \pm 0.08$ (mean $\pm \mathrm{SD}$ ) fold that of the control after Ang IV stimulation $(n=6)$. Two specific bands may also reflect a different modification status of this protein.

the discovery and cloning of IRAP, a binding site and a probable receptor (AT4) of Ang IV. Our study demonstrates that Ang IV has an inhibitory effect on proliferation of neural cells. We tested Ang IV's effect on cell proliferation in HEK293, N2A and 2F1 cell lines which express no, medium levels and high levels of IRAP, respectively. In line with their IRAP level, Ang IV barely, slightly and markedly inhibited their growth, demonstrating that this effect is dependent of IRAP.

Transient protein modification is an essential regulatory mechanism for many biological processes. One type of transient modification, phosphorylation, is predicted to occur on nearly one-third of the proteins encoded in the human genome (Ceulemans and Bollen, 2004). The fully sequenced human genome contains about 30 putative protein Ser/Thr phosphatases (PSPs), which comprise three major families: phosphoprotein phosphatases (PPPs), metal-dependent protein phosphatases (PPMs), and aspartate-based phosphatases represented by FCP/SCP (Shi, 2009). PP1 is a representative member of the PPP family and is universally expressed in all eukaryotic cells. It plays an important part in a wide range of cellular processes, including apoptosis, membrane receptor and channel regulation, meiosis and cell division, protein synthesis, and cytoskeletal reorganization (Cohen, 2002; Ceulemans and Bollen, 2004). In the nervous system, PP1 regulates short-term events such as the phosphorylation status of receptors, ion channels, and signaling proteins, as well as long term events requiring changes in protein synthesis, gene expression, and neuronal morphology that together modify neuronal plasticity (Gräff et al., 2010).

The activity of PP1 can be regulated directly by proteins like CDKs which inhibit PP1 via phosphorylating its Thr320 site. Another mechanism by which PP1 achieves its precise substrate specificity is by combining many kinds of regulatory subunits (Bollen, 2001; Cohen, 2002). Spinophilin/neurabin II (spn) is one of these regulatory subunits and directs the catalytic subunit of this PP1 (PP1c) close to some of its substrates (Satoh et al., 1998; Sarrouilhe et al., 2006). Morphological studies established that spn is enriched at the plasma membrane of cells although the protein is also expressed widely throughout the cytoplasm (Smith et al., 1999; Tsukada et al., 2003). Intriguingly, when two serines in and near the $\mathrm{NH}_{2}-$ terminal actin binding domain of spn are phosphorylated, the spn/PP1 complex tends to dissociate from the membraneassociated fraction to the cytosol (Hsieh-Wilson et al., 2003). Our results indicate that spn changes its localization in the cell when stimulated with Ang IV. This re-distribution could target PP1 to some certain of its substrates, resulting in changes in cellular behavior. We also found that the putative AT4 receptor IRAP is involved in the regulation of PP1 and spn. In 2F1 cells, spn was found to have an increased expression after treated with Ang IV. At the same time, the phosphorylation level of PP1 at Thr320 was inhibited. These changes are exactly the same as happened in N2A cell. But no such phenomenon was detected in HEK293 cells (Fig. S1).

Many reports have shown that PP1 and spn take part in regulating cell proliferation via $\mathrm{P} 70^{\mathrm{S} 6 \mathrm{~K}}$, the activation of which is important for progression through $\mathrm{G}_{1}$ (Chou and Blenis, 1995). An interaction between spn and $P 70^{\text {S6K }}$ has been demonstrated in vitro (Buchsbaum et al., 2003). Interestingly, the binding of PP1 and P70 ${ }^{\mathrm{S} 6 \mathrm{~K}}$ to spn is mutually exclusive, probably because PP1 and the kinase compete for overlapping binding sites, or PP1 activity prevents $\mathrm{P}^{2} 0^{\text {S6K }}$ kinase from binding (Burnett et al., 1998). When associated with spn, PP1 dephosphorylates $\mathrm{P} 70^{\mathrm{S} 6 \mathrm{~K}}$, therefore inhibiting its activity and dissociating it from spn/PP1. A similar mechanism is found in the vitamin $D$ receptor mediated pathway, where ligand-activated PP1 dephosphorylates $\mathrm{P} 70^{\mathrm{S} 6 \mathrm{~K}}$, thus inactivating it and preventing its recruitment from this receptor. This process is argued to contribute to vitamin D-induced cell cycle arrest (Bettoun et al., 2002). Our results also show that, as PP1 activity is upregulated, the phosphorylation level of $\mathrm{P} 70^{\mathrm{S} 6 \mathrm{~K}}$ decreases, even though increased expression of spn was detected. This may explain the observed effect of Ang IV on inhibiting N2A cell proliferation and the resulting cell cycle arrest.

Another important protein which plays a key role in the regulation of the cell cycle is pRB. pRB is dephosphorylated during mitosis, and the active, hypophosphorylated form inhibits cell cycle progression during early and mid- $\mathrm{G}_{1}$. PP1 has been implicated as the major pRB phosphatase in vivo (Yan and Mumby, 1999). This has been clearly demonstrated as a constitutively active T320A mutant of PP1 $\alpha$ prevents retinoblastoma protein $\mathrm{Rb}$ phosphorylation in late $\mathrm{G}_{1}$ cells and causes cell cycle arrest (Berndt et al., 1997). On the other hand, loss of spn reduces levels of PPP1CA, resulting in the retention of 
hyperphosphorylated pRB (Molina-Pinelo et al., 2011). In our research, Ang IV had the ability to delay the cell from entering $S$ phase, causing a $G_{1} / S$ cell arrest. This phenomenon is consistent with decreased $\mathrm{pRB}$ phosphorylation compared to the control. This is most probably due to up-regulation of PP1 $\alpha$ with its Thr 320 site dephosphorylated.

At the same time, pRB is a well-known substrate of CDKs. In mammalian cells, RB-family proteins could be phosphorylated by cyclin-D-CDK4/6 (Ewen et al., 1993; Kato et al., 1993) and cyclin-E-CDK2 (Akiyama et al., 1992; Hinds et al., 1992) cooperatively. Phosphorylation of the pRB family proteins by CDKs during $\mathrm{G}_{1}$ phase causes $\mathrm{pRB}$ to derepress E2Fs, allowing the transcription of E2F target genes that stimulate progression into S phase (Dyson, 1998). So, there is another possibility that Ang IV may decrease the phosphorylation level of pRB indirectly by inhibiting the activity of CDK. In fact, many CDK inhibitors (CKIs) do play an important role in arresting the cell cycle in $\mathrm{G}_{1}$ phase. So, the relationship between Ang IV and $\mathrm{CDKs}$ remains to be further investigated.

Here, we have described a complex relationship between Ang IV stimulation and PP1 activity in neuronal cells. We propose that addition of Ang IV increases the activity of PP1 by increasing spn expression and decreasing its inhibitory phosphorylation at Thr320. Accordingly, the phosphorylation level of some certain proteins is down-regulated. This function may be directly mediated by the raised activity of PP1, or indirectly by inhibiting the activity of some protein kinases, such as CDKs. By doing so, Ang IV could regulate the proliferation of neuronal cells.

\section{MATERIALS AND METHODS}

Antibodies and reagents

Spinophilin (Neurabin II) antibody was purchased from Santa Cruz

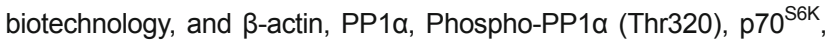
Phospho-p70S6 (Thr389) kinase and HRP (horseradish peroxidase)conjugated secondary antibody were purchased from Cell Signaling Technology. Rb and Phospho-Rb (S807) were purchased from Bioworld Technology, Inc. FITC-labeled phalloidin, CY5 combined antirabbit second antibody, DAPI and propidium iodide were purchased from Invitrogen, USA. Western Lightning Plus-ECL enhanced chemiluminescence substrate was obtained from PerkinElmer. Ang IV (ValTyr-Ile-His-Pro-Phe-OH) was obtained from Bachem (Bubendorf, Switzerland). Cell Counting Kit-8 (CCK8) was purchased from Dojindo Molecular Technologies, Inc, Japan. L-Arginine: $\mathrm{HCl}\left(\mathrm{U}-{ }^{13} \mathrm{C}_{6},{ }^{15} \mathrm{~N}_{4}\right)$ and L-Lysine: $2 \mathrm{HCl}\left({ }^{13} \mathrm{C}_{6},{ }^{15} \mathrm{~N}_{2}\right)$ were from Cambridge Isotope laboratories Inc., Andover MA. Dialyzed FBS was purchased from Biological Industries (Kibbutz Beit Haemek, Israel).

\section{Cell culture}

N2A cells, L6 cells and HEK293 cells were cultured in DMEM/F12, a-MEM and DMEM medium (Gibco), respectively, with $10 \%$ fetal bovine serum (Hyclone) in a $37^{\circ} \mathrm{C}$ incubator with $5 \% \mathrm{CO}_{2}$.

\section{SILAC and sample preparation for LC-MS/MS analysis}

A SILAC strategy was used for quantitative phosphoproteome analysis as previously described (Cui et al., 2009). Briefly, N2A cells were cultured in DMEM/F12 supplemented with $8 \%$ dialyzed FBS plus $2 \%$ normal FBS and light $(\mathrm{L})$ or heavy $(\mathrm{H})$ arginine and lysine isotopes. Labeling of cells was performed for at least seven population doublings. After labeling efficiency reached more than $98 \%$, cells with different labels were respectively treated with/without $10 \mathrm{nmol} / \mathrm{L}$ Ang IV for $30 \mathrm{~min}$. After washing with ice-cold PBS, cells were scraped into $8 \mathrm{~mol} / \mathrm{L}$ urea containing a protease inhibitor cocktail and phosphatase inhibitor (Roche, Basel, Switzerland), and were sonicated to lyse the cells. After centrifugation for $30 \mathrm{~min}$ at 20,000 $\mathrm{g}$ in a bench-top centrifuge (Thermo Fisher Scientific, Waltham, MA), the supernatants were collected and protein concentrations were measured using the Pierce BCA protein assay according to the manufacturer's protocol. Protein extracts from $\mathrm{L}$ and $\mathrm{H}$ cells were adjusted to an equal protein concentration and then mixed at a 1:1 ratio. Protein mixtures were then reduced with $10 \mathrm{mmol} / \mathrm{L}$ DTT for $1 \mathrm{~h}$, and alkylated with $40 \mathrm{mmol} / \mathrm{L}$ iodoacetamide in the dark for $45 \mathrm{~min}$ at room temperature. $40 \mathrm{mmol} / \mathrm{L}$ DTT was added to quench the iodoacetamide for $30 \mathrm{~min}$ at room temperature. After diluting $8 \mathrm{~mol} / \mathrm{L}$ urea to $1.6 \mathrm{~mol} / \mathrm{L}$ with $25 \mathrm{mmol} / \mathrm{L} \mathrm{NH}_{4} \mathrm{HCO}_{3}$, sequence grade trypsin was added at a ratio of 1:50 (enzyme: protein) and proteins were then digested at $37^{\circ} \mathrm{C}$ overnight. Tryptic digestion was stopped by adding formic acid to a final concentration of $1 \%$. The protein digests were separated first into 9 fractions with self-packed C18 columns and then each fraction was submitted to $\mathrm{TiO}_{2}$ phosphopeptide enrichment. The resulting phosphopeptides were combined and analyzed using an online 2D-LC-MS/MS on a LTQ Orbitrap mass spectrometer (Thermo Scientific) as described (Hou et al., 2010). Spectra were interpreted using MaxQuant version 1.3.0.5.

\section{Cell proliferation assays}

Cells were cultured in 96-well plates to a total volume of $90 \mathrm{~mL}$ and $30 \%$ density. Serial dilutions of Ang IV were added to different wells, and incubated for $18 \mathrm{~h} .10 \mathrm{~mL}$ of CCK8 reaction solution was added to each well and incubated at $37^{\circ} \mathrm{C}$ for $1 \mathrm{~h}$. Absorption at $630 \mathrm{~nm}$ was detected to determine cell density in each well.

\section{Immunoblotting}

N2A cells were serum-starved for at least $6 \mathrm{~h}$ before treatment with $10 \mathrm{nmol} / \mathrm{L}$ Ang IV. After the times indicated, they were washed twice with PBS and harvested with SDS sample buffer $(50 \mathrm{mmol} / \mathrm{L}$ Tris- $\mathrm{HCl}$ (pH 6.8), $10 \mathrm{mmol} / \mathrm{L}$ DTT, $2 \%$ SDS, $0.025 \%$ bromophenol blue, $12.5 \%$ glycerol). Proteins were separated by SDS-PAGE and electrotransferred to nitrocellulose membranes, then detected by immunoblotting with the antibodies indicated, followed by HRP (horseradish peroxidase)-conjugated secondary Abs. $\beta$-actin was assayed to ensure equal loading of total protein in each lane. Immunoreactive bands were visualized with Western Lightning Plus-ECL enhanced chemiluminescence substrate as indicated, and densitometric analyses were carried out using Image $(\mathrm{NIH})$.

Cell cycle analysis

HEK293 and N2A cells were cultured as described above. Treated 
cells were incubated with Ang IV at a final concentration of $100 \mathrm{nmol} / \mathrm{L}$ for more than $10 \mathrm{~h}$, while untreated cells were used as controls. Cells were then trypsinized, washed twice with cold PBS, centrifuged at $2000 \mathrm{r} / \mathrm{min}$, and resuspended in $300 \mu \mathrm{L}$ cold PBS. $700 \mu \mathrm{L}$ cold methanol was added gently drop by drop to fix the cells. After leaving at $4^{\circ} \mathrm{C}$ for $18 \mathrm{~h}$, the cells were washed twice with PBS, resuspended in $200 \mu \mathrm{L}$ PBS and incubated with $50 \mu \mathrm{L}$ RNaseA (final concentration, $0.1 \mathrm{mg} / \mathrm{mL}$ ) at $37^{\circ} \mathrm{C}$ for at least $30 \mathrm{~min}$. Cells were stained with $50 \mu \mathrm{L}$ propidium iodide $(0.2 \mathrm{mg} / \mathrm{mL}$ final concentration) for $1 \mathrm{~h}$ and then analyzed by flow cytometry to measure the distribution of cells in different phases of the cell cycle. The percentage of cells in the $G_{0}-G_{1}, S$, and $\mathrm{G}_{2}-\mathrm{M}$ phases was calculated using Modfit (Verity House Software, Inc.) Results shown are representative of five separate experiments.

\section{Confocal microscopy}

Cells were cultured in a glass-bottom 96-well plate. After treatment with $10 \mathrm{nmol} / \mathrm{L}$ Ang IV for $4 \mathrm{~h}$, they were washed twice with PBS, blocked with $5 \%$ goat serum and then incubated with rabbit-derived anti-spinophilin antibody for $2 \mathrm{~h}$. Cells were then incubated with FITC-labeled phalloidin, CY5 combined anti-rabbit second antibody and DAPI to detect F-actin, spn and nuclei, respectively. Images were captured under a FV500 confocal laser scanning microscope (Olympus Optical Co., Tokyo, Japan). Fluorescence intensity was calculated with Image $\mathrm{J}$ software. At least 200 cells were recorded for each group.

\section{Statistical analysis}

Statistical analyses were performed using two-tailed unpaired $t$-tests. $P<0.05$ was considered statistically significant.

\section{ACKNOWLEDGEMENTS}

We thank Dr. Junjie Hou for useful comments on the manuscript. We are also grateful for the guidance and help of Xudong Zhao, Su Liu and Zhenwei Yang with operating certain experimental instruments. This work was supported by the Knowledge Innovation Project of the Chinese Academy of Sciences (KSCX1-YW-02), and the National Natural Science Foundation of China (Grant No. 30801416).

\section{ABBREVIATIONS}

Ang IV, angiotensin IV; P70 ${ }^{\text {S6K }}$, P70 S6 kinase; PP1, protein phosphorylase 1 ; pRB, the retinoblastoma protein; spn, spinophillin

\section{COMPLIANCE WITH ETHICS GUIDELINES}

Dan Wang, Peng Xue, Xiu Lan Chen, Zhen Sheng Xie, Fu Quan Yang, Li Zheng and Tao Xu declare that they have no conflict of interest.

This article does not contain any studies with human or animal subjects performed by the any of the authors.

\section{REFERENCES}

Akiyama, T., Ohuchi, T., Sumida, S., Matsumoto, K., and Toyoshima, K. (1992). Phosphorylation of the retinoblastoma protein by cdk2. Proc Natl Acad Sci U S A 89, 7900-7904.

Albiston, A.L., McDowall, S.G., Matsacos, D., Sim, P., Clune, E., Mustafa, T., Lee, J., Mendelsohn, F.A., Simpson, R.J., Connolly,
L.M., et al. (2001). Evidence that the angiotensin IV (AT(4)) receptor is the enzyme insulin-regulated aminopeptidase. J Biol Chem 276, 48623-48626.

Allen, P.B., Ouimet, C.C., and Greengard, P. (1997). Spinophilin, a novel protein phosphatase 1 binding protein localized to dendritic spines. Proc Natl Acad Sci U S A 94, 9956-9961.

Berndt, N. (1999). Protein dephosphorylation and the intracellular control of the cell number. Front Biosci 4, D22-42.

Berndt, N., Dohadwala, M., and Liu, C.W.Y. (1997). Constitutively active protein phosphatase $1 \alpha$ causes Rb-dependent $\mathrm{G} 1$ arrest in human cancer cells. Curr Biol 7, 375-386.

Bettoun, D.J., Buck II, D.W., Lu, J., Khalifa, B., Chin, W.W., and Nagpal, S. (2002). A vitamin D receptor-Ser/Thr phosphatase-p70 S6 kinase complex and modulation of its enzymatic activities by the ligand. J Biol Chem 277, 24847-24850.

Bialojan, C., and Takai, A. (1988). Inhibitory effect of a marine-sponge toxin, okadaic acid, on protein phosphatases. Specificity and kinetics. Biochem J 256, 283-290.

Bollen, M. (2001). Combinatorial control of protein phosphatase-1. Trends Biochem Sci 26, 426-431.

Braszko, J.J., Kupryszewski, G., Witczuk, B., and Wisniewski, K. (1988). Angiotensin II-(3-8)-hexapeptide affects motor activity, performance of passive avoidance and a conditioned avoidance response in rats. Neuroscience 27, 777-783.

Buchsbaum, R.J., Connolly, B.A., and Feig, L.A. (2003). Regulation of p70 S6 kinase by complex formation between the Rac guanine nucleotide exchange factor (Rac-GEF) Tiam1 and the scaffold spinophilin. J Biol Chem 278, 18833-18841.

Burnett, P.E., Blackshaw, S., Lai, M.M., Qureshi, I.A., Burnett, A.F., Sabatini, D.M., and Snyder, S.H. (1998). Neurabin is a synaptic protein linking p70 S6 kinase and the neuronal cytoskeleton. Proc Natl Acad Sci U S A 95, 8351-8356.

Ceulemans, H., and Bollen, M. (2004). Functional diversity of protein phosphatase-1, a cellular economizer and reset button. Physiol Rev 84, 1-39.

Chansel, D., Czekalski, S., Vandermeersch, S., Ruffet, E., FournieZaluski, M.C., and Ardaillou, R. (1998). Characterization of angiotensin IV-degrading enzymes and receptors on rat mesangial cells. Am J Physiol 275, F535-542.

Chansel, D., Vandermeersch, S., Oko, A., Curat, C., and Ardaillou, R. (2001). Effects of angiotensin IV and angiotensin-(1-7) on basal and angiotensin II-stimulated cytosolic Ca2+ in mesangial cells. Euro J Pharm 414, 165-175.

Cheng, A., Dean, N.M., and Honkanen, R.E. (2000). Serine/threonine protein phosphatase type $1 \mathrm{y} 1$ is required for the completion of cytokinesis in human A549 lung carcinoma cells. J Biol Chem 275, 1846-1854.

Chou, M.M., and Blenis, J. (1995). The $70 \mathrm{kDa}$ S6 kinase: regulation of a kinase with multiple roles in mitogenic signalling. Curr Opin Cell Biol 7, 806-814.

Chung, J., Grammar, T.C., Lemon, K.P., Kazlauskas, A., and Blenis, J. (1994). PDGF-and insulin-dependent pp70S6K activation mediated by phosphatidylinositol-3-OH kinase Nature 370, 71-75.

Cohen, P.T.W. (2002). Protein phosphatase 1-targeted in many directions. J Cell Sci 115, 241-256.

Cui, Z., Chen, X., Lu, B., Park, S.K., Xu, T., Xie, Z., Xue, P., Hou, J., Hang, H., and Yates, J.R. (2009). Preliminary quantitative profile 
of differential protein expression between rat L6 myoblasts and myotubes by stable isotope labeling with amino acids in cell culture. Proteomics 9, 1274-1292.

Dostal, D.E., Murahashi, T., and Peach, M.J. (1990). Regulation of cytosolic calcium by angiotensins in vascular smooth muscle. Hypertension 15, 815-822.

Dou, Q.P., An, B., and Will, P.L. (1995). Induction of a retinoblastoma phosphatase activity by anticancer drugs accompanies p53independent G1 arrest and apoptosis. Proc Natl Acad Sci U S A 92, 9019-9023.

Dulin, N., Madhun, Z.T., Chang, C.H., Berti-Mattera, L., Dickens, D., and Douglas, J.G. (1995). Angiotensin IV receptors and signaling in opossum kidney cells. Am J Physiol 269, F644-652.

Dyson, N. (1998). The regulation of E2F by pRB-family proteins. Genes Dev 12, 2245-2262.

Ewen, M.E., Sluss, H.K., Sherr, C.J., Matsushime, H., Kato, J.-y., and Livingston, D.M. (1993). Functional interactions of the retinoblastoma protein with mammalian D-type cyclins. Cell 73, 487-497.

Fernandez, A., Brautigan, D.L., and Lamb, N. (1992). Protein phosphatase type 1 in mammalian cell mitosis: chromosomal localization and involvement in mitotic exit. J Cell Biol 116, 1421-1430.

Fernando, R.N., Albiston, A.L., and Chai, S.Y. (2008). The insulinregulated aminopeptidase IRAP is colocalised with GLUT4 in the mouse hippocampus-potential role in modulation of glucose uptake in neurones? Euro J Neurosci 28, 588-598.

Gräff, J., Koshibu, K., Jouvenceau, A., Dutar, P., and Mansuy, I.M. (2010). Protein phosphatase 1-dependent transcriptional programs for long-term memory and plasticity. Learn Mem 17, 355-363.

Handa, R.K. (2001). Characterization and signaling of the AT(4) receptor in human proximal tubule epithelial (HK-2) cells. J Am Soc Nephrol 12, 440-449.

Hinds, P.W., Mittnacht, S., Dulic, V., Arnold, A., Reed, S.I., and Weinberg, R.A. (1992). Regulation of retinoblastoma protein functions by ectopic expression of human cyclins. Cell 70, 993-1006.

Hou, J., Cui, Z., Xie, Z., Xue, P., Wu, P., Chen, X., Li, J., Cai, T., and Yang, F. (2010). Phosphoproteome analysis of rat L6 myotubes using reversed-phase $\mathrm{C} 18$ prefractionation and titanium dioxide enrichment. J Proteome Res 9, 777-788.

Hsieh-Wilson, L.C., Benfenati, F., Snyder, G.L., Allen, P.B., Nairn, A.C., and Greengard, P. (2003). Phosphorylation of spinophilin modulates its interaction with actin filaments. J Biol Chem 278, 1186-1194.

Kato, J., Matsushime, H., Hiebert, S.W., Ewen, M.E., and Sherr, C.J. (1993). Direct binding of cyclin $D$ to the retinoblastoma gene product $(\mathrm{pRb})$ and $\mathrm{pRb}$ phosphorylation by the cyclin D-dependent kinase CDK4. Genes Dev 7, 331-342.

Lee, J., Albiston, A.L., Allen, A.M., Mendelsohn, F.A., Ping, S.E., Barrett, G.L., Murphy, M., Morris, M.J., McDowall, S.G., and Chai, S.Y. (2004). Effect of I.C.V. injection of AT4 receptor ligands, NLE1angiotensin IV and LVV-hemorphin 7, on spatial learning in rats. Neuroscience 124, 341-349.

Lew, R.A., Mustafa, T., Ye, S., McDowall, S.G., Chai, S.Y., and Albiston, A.L. (2003). Angiotensin AT4 ligands are potent, competitive inhibitors of insulin regulated aminopeptidase (IRAP). J Neurochem 86, 344-350.

Li, T., Chalifour, L.E., and Paudel, H.K. (2007). Phosphorylation of protein phosphatase 1 by cyclin-dependent protein kinase 5 during nerve growth factor-induced PC12 cell differentiation. J Biol Chem 282, 6619-6628.

Li, Y.D., Block, E.R., and Patel, J.M. (2002). Activation of multiple signaling modules is critical in angiotensin IV-induced lung endothelial cell proliferation. Am J Physiol Lung Cell Mol Physiol 283, L707716.

Liu, C.W.Y., Wang, R.H., Dohadwala, M., Schönthal, A.H., VillaMoruzzi, E., and Berndt, N. (1999). Inhibitory phosphorylation of PP1 a catalytic subunit during the G1/S transition. J Biol Chem 274, 29470-29475.

Molina-Pinelo, S., Ferrer, I., Blanco-Aparicio, C., Peregrino, S., Pastor, M.D., Alvarez-Vega, J., Suarez, R., Verge, M., Marin, J.J., and Hernandez-Losa, J. (2011). Down-regulation of spinophilin in lung tumours contributes to tumourigenesis. J Pathol 225, 73-82.

Ragusa, M.J., Dancheck, B., Critton, D.A., Nairn, A.C., Page, R., and Peti, W. (2010). Spinophilin directs protein phosphatase 1 specificity by blocking substrate binding sites. Nat Struct Mol Biol 17, 459-464.

Ruiz-Ortega, M., Esteban, V., and Egido, J. (2007). The regulation of the inflammatory response through nuclear factor-kappab pathway by angiotensin IV extends the role of the renin angiotensin system in cardiovascular diseases. Trends Cardiovasc Med 17, 19-25.

Sarrouilhe, D., Di Tommaso, A., Metaye, T., and Ladeveze, V. (2006). Spinophilin: from partners to functions. Biochimie 88, 1099-1113.

Satoh, A., Nakanishi, H., Obaishi, H., Wada, M., Takahashi, K., Satoh, K., Hirao, K., Nishioka, H., Hata, Y., and Mizoguchi, A. (1998). Neurabin-II/spinophilin. J Biol Chem 273, 3470-3475.

Shi, Y. (2009). Serine/threonine phosphatases: mechanism through structure. Cell 139, 468-484.

Shibasaki, Y., Mori, Y., Tsutumi, Y., Masaki, H., Sakamoto, K., Murasawa, S., Maruyama, K., Moriguchi, Y., Tanaka, Y., Iwasaka, T., et al. (1999). Differential kinetics of circulating angiotensin IV and II after treatment with angiotensin II type 1 receptor antagonist and their plasma levels in patients with chronic renal failure. Clin Nephrol 51, 83-91.

Smith, F.D., Oxford, G.S., and Milgram, S.L. (1999). Association of the D2 dopamine receptor third cytoplasmic loop with spinophilin, a protein phosphatase-1-interacting protein. J Biol Chem 274, 19894-19900.

Takai, A., Bialojan, C., Troschka, M., and Rüegg, J. (1987). Smooth muscle myosin phosphatase inhibition and force enhancement by black sponge toxin. FEBS Lett 217, 81-84.

Terry-Lorenzo, R.T., Carmody, L.C., Voltz, J.W., Connor, J.H., Li, S., Smith, F.D., Milgram, S.L., Colbran, R.J., and Shenolikar, S. (2002). The neuronal actin-binding proteins, neurabin I and neurabin II, recruit specific isoforms of protein phosphatase-1 catalytic subunits. J Biol Chem 277, 27716-27724.

Tsukada, M., Prokscha, A., Oldekamp, J., and Eichele, G. (2003). Identification of neurabin II as a novel doublecortin interacting protein. Mech Dev 120, 1033-1043.

Vivo, M., Calogero, R.A., Sansone, F., Calabro, V., Parisi, T., Borrelli, L., Saviozzi, S., and La Mantia, G. (2001). The human tumor suppressor arf interacts with spinophilin/neurabin II, a type 1 proteinphosphatase-binding protein. J Biol Chem 276, 14161-14169.

Wang, P., Bai, Y., Song, B., Wang, Y., Liu, D., Lai, Y., Bi, X., and Yuan, Z. (2011). PP1A-mediated dephosphorylation positively regulates YAP2 activity. PloS One 6, e24288. 
Wright, J.W., Stubley, L., Pederson, E.S., Kramar, E.A., Hanesworth, J.M., and Harding, J.W. (1999). Contributions of the brain angiotensin IV-AT4 receptor subtype system to spatial learning. J Neurosci 19, 3952-3961.
Yan, Y., and Mumby, M.C. (1999). Distinct Roles for PP1 and PP2A in Phosphorylation of the Retinoblastoma Protein PP2A REGULATES THE ACTIVITIES OF G1 CYCLIN-DEPENDENT KINASES. J Biol Chem 274, 31917-31924. 